\title{
DERECHOS DE NECESIDAD AGRESIVA Y DEBERES DE TOLERANCIA
}

\author{
Jesús-María Silva Sánchez *
}

\section{Introducción.}

Es pacífico concluir que quien obra en el marco del denominado "estado de necesidad justificante" no actúa de modo penalmente antijurídico. Con todo, existen dudas acerca del exacto significado de esa afirmación ${ }^{2}$. En concreto: sobre si quiere decir sólo que la conducta del sujeto no está prohibida por el Derecho Penal ${ }^{3}$, de modo que no se da el primero de los presupuestos de aplicación de una norma de sanción jurídico-penal; o si quiere decir, además, que tal conducta no infringe norma de conducta alguna, de modo que está permitida por el Derecho en general; o si, además, significa que el sujeto está ejerciendo un derecho (el denominado derecho de necesidad-Notrecht-).

\footnotetext{
* Catedrático de Derecho Penal, Universidad Pompeu Fabra de Barcelona.

${ }^{1}$ Cuyo alcance no pongo en cuestión en este texto, remitiéndome, por tanto, a su caracterización por la doctrina dominante, así como al tenor del § 34 StGB.

${ }^{2}$ Cfr. las referencias históricas en Renzikowski, Notstand und Notwehr, Berlin 1994, p. 187 , notas $122,123$.

${ }^{3}$ Como es sabido, para un sector doctrinal las cosas no son exactamente así, sino que la conducta justificada sigue estando genéricamente prohibida y sólo excepcionalmente permitida. Esta posición tiene que ver con una concepción de la relación entre tipicidad y antijuricidad o, en otros términos, de la relación de las permisiones con las normas de mandato y prohibición distinta de la que aquí se sigue. Pero, en todo caso, también para este punto de vista la conclusión es que la conducta justificada no es indebida, por lo que no es necesario, a los efectos que aquí interesan, profundizar en ese debate, en parte superado.
} 
Esto último es lo que aquí interesa de modo especial. Ciertamente, si el sujeto necesitado (o quien le ayude, en los términos del denominado auxilio necesario) tiene éxito en su empeño, se concluye por lo general que no obra antijurídicamente y, por lo tanto, no se le sanciona penalmente. Expresado de otro modo: el carácter no prohibido de la conducta justificada implica, en todo caso, que los órganos del Estado tienen el deber de tolerarla ${ }^{4}$; éstos no pueden impedir su realización y, desde luego, una vez realizada no pueden someterla a pena. Pero ¿qué ocurre si el tercero afectado por la conducta del sujeto necesitado o de su auxiliador reacciona impidiendo que éstos logren su propósito? Más concretamente: ¿Incurre en algún género de responsabilidad el sujeto afectado por la conducta necesaria - $u$ otro sujeto que, a su vez, se ponga de su parte- que tiene éxito en impedir la conducta del necesitado o su auxiliador? Y, de responderse afirmativamente a lo anterior, ¿en qué responsabilidad ${ }^{5}$ En estrecha relación con esto se halla todavía una pregunta más: si el sujeto afectado por la conducta necesaria se opone a ella, ¿en qué términos puede reaccionar, entonces, el sujeto necesitado para tratar de neutralizar tal oposición? ${ }^{6}$

Una primera posibilidad sería afirmar que si el tercero afectado por la conducta necesaria u otro que obre por su cuenta impiden que dicha conducta tenga éxito, no sucede nada. Es decir, que el tercero afectado por la conducta del necesitado o de su auxiliador no tiene el deber de soportarla; y, por tanto, si él -o alguien en su favor- consiguen

\footnotetext{
${ }^{4}$ En cambio, los órganos del Estado no tienen el deber de tolerar conductas sólo disculpadas.

${ }^{5}$ Esta pregunta por la responsabilidad admite diversas variantes. Por ejemplo: ¿qué ocurre si el tercero afectado -o su auxiliador- intentan impedir la conducta del necesitado y no lo consiguen? ¿qué ocurre si impiden la conducta del necesitado sin quererlo, pero por imprudencia?

${ }^{6}$ No deja de resultar sorprendente que, en el marco de una monografía de más de trescientas cincuenta apretadas páginas sobre el estado de necesidad justificante como la de Pawlik, Der rechtfertigende Notstand, Berlin 2002, estas preguntas queden sin una respuesta mínimamente precisa: cfr. pp. 154-156, especialmente el final de la nota 23.
} 
neutralizarla, de ahí no se deriva la constatación de infracción ni la imposición de sanción alguna. Desde luego, la aceptación de esta posibilidad tiene algo de paradójico, pues conduce a la siguiente conclusión: el que obra en estado de necesidad justificante, si tiene éxito, es decir, consigue la causación del mal menor necesario para evitar el mal mayor, no es sancionado. Pero, antes de conseguirlo, es decir en el momento de actuar, el Derecho no le respalda frente a quien se oponga a su conducta, de modo que, si es este último quien tiene éxito, tampoco el Estado le somete a pena alguna. Y el primero no podría reclamar el auxilio de los órganos del Estado para que le ayudaran a neutralizar la resistencia del afectado.

Esto, de ser cierto, pondría de relieve la posición, significativamente débil, de quien actúa en estado de necesidad realizando algo no prohibido pero sin tener un derecho a realizarlo. Un derecho que daría lugar, como lógico correlato, al deber de terceros de tolerar su realización ${ }^{7}$. Pues dicho sujeto sólo vería protegidas sus posiciones de hecho ya alcanzadas; pero no podría contar con el respaldo del Derecho para alcanzarlas ${ }^{8}$.

Una segunda posibilidad es afirmar que, en efecto, tanto el tercero afectado como cualesquiera otros sujetos están obligados a no impedir la conducta justificada del necesitado o de su auxiliador. Esta segunda posibilidad es la acogida cuando en Derecho Penal se alude a la existencia

${ }^{7}$ Coincidente Renzikowski, Notstand, p. 193.

${ }^{8}$ En la práctica, la situación del sujeto se aproximaría a la del estado de necesidad disculpante. No extraña, en este sentido, que Kant rechazara la propia posibilidad de un estado de necesidad justificante, al negar la existencia de un "derecho de necesidad". Cfr. últimamente sobre ello, Pawlik, Notstand, pp. 18 y ss. De todos modos, como indica Perron, Rechtfertigung und Entschuldigung im deutschen und spanischen Recht, Baden-Baden 1988, p. 87, el derecho de injerencia y el correlativo deber de tolerancia no constituyen propiedades necesarias ni específicas de las causas de justificación. La posición opuesta era sostenida, por ejemplo, por Maurach, Tratado de Derecho penal (trad. Córdoba Roda), I, Barcelona 1962, p. 367: "toda causa de justificación confiere un propio derecho de necesidad al agente"; siguiéndole, Bacigalupo, Principios de Derecho penal, PG, 4ª edic, Madrid 1997, p. 267, quien ve en el deber de tolerancia la contrapartida de la justificación. 
de deberes de tolerancia o de sacrificio (Duldungspflichten, Aufopferungspflichten) en relación con, al menos, algunas causas de justificación, entre las que se cuenta el estado de necesidad agresivo, objeto concreto de estas páginas ${ }^{9}$. En efecto, con ello se pretende concretamente hacer referencia a que las conductas típicas amparadas por ciertas causas de justificación ${ }^{10}$ constituyen el ejercicio de un derecho de intromisión del sujeto justificado en la esfera de un tercero, que debe ser soportado por éste y no impedido por nadie. La imposición legal de este deber de tolerancia se esgrime incluso como "prueba" del carácter justificado -en sentido estricto- de la intervención ${ }^{11}$. Es decir, precisamente porque habría un deber de tolerancia podría hablarse de un verdadero “derecho de necesidad". En cambio, más allá del deber de tolerancia del afectado no habría tal derecho de necesidad, aunque sí podría llegar a sostenerse quizá que el hecho no está prohibido penalmente o que no constituye un injusto penal.

Resulta prácticamente seguro que la naturaleza del deber de tolerancia del Estado, al que se aludió más arriba, y la del deber de tolerancia del afectado (y otros terceros) con respecto a la conducta típica y justificada, son distintas. La fuente del deber de tolerancia del Estado se halla en el propio carácter no prohibido de la conducta justificada. En cambio, el deber de tolerancia del afectado y de otros terceros no se deriva sin más

\footnotetext{
${ }^{9}$ Hruschka, Strafrecht nach logisch-analytischer Methode, Berlin 1983, pp. 89 y ss; Kühl, Freiheit und Solidarität bei den Notrechten, Festschrift für H.J. Hirsch zum 70. Geburtstag, Berlin/ New York 1999, pp. 259 y ss., 266. Cfr., en cambio, el escepticismo de Freund acerca de la apreciación automática de deberes de tolerancia en relación con las conductas amparadas por una causa de justificación (Duldungspflichtautomatik), en Münchener Kommentar zum StGB, Band 1, München 2003, consideraciones previas a los $\S \S 13$ y ss, $\mathrm{n}^{\mathrm{o}}$ marg. 194, 208 y ss, 210.

${ }^{10}$ Perron, Rechtfertigung, p. 86; Günther, La clasificación de las causas de justificación en Derecho Penal (trad. Luzón Peña), en Luzón/ Mir (coord.), Causas de justificación y de atipicidad en Derecho Penal, Pamplona 1995, pp. 45 y ss., 54.

${ }^{11}$ Stratenwerth, Strafrecht AT, I, Die Straftat, 4ª edic., Köln 2000, 9/ 48.
} 
del carácter no prohibido de la conducta justificada, sino que su fuente debe de hallarse en una norma adicional. La cuestión es determinar la fuente del deber de tolerancia de terceros con respecto a la conducta realizada en estado de necesidad agresivo. Si se trata simplemente de un deber moral o de un deber jurídico y, más concretamente, jurídico-penal. En este último caso, procedería determinar si su infracción da lugar a sanción y a qué concreta sanción.

\section{El fundamento del deber de tolerar conductas realizadas en estado de necesidad agresivo.}

\subsection{El contenido del deber de tolerancia.}

Puede afirmarse que existe acuerdo en que la imposición de un deber de tolerancia implica, para el titular de una determinada esfera de derechos, la inexistencia de un derecho subjetivo de exclusión de terceros de dicha esfera ${ }^{12}$. Ello se traduce en la imposibilidad de justificar un acto concreto de exclusión de dichos terceros sobre la base de la legítima defensa o del propio estado de necesidad ${ }^{13}$. Y, consiguientemente, aunque esta cuestión resulta mucho menos clara en la discusión doctrinal, en la sanción jurídica (supuestamente, jurídico-penal) del referido acto de exclusión fáctica de terceros, que constituiría una "vía de hecho". Expresado de modo inverso, todo ello implica que el sujeto que accede a

\footnotetext{
${ }^{12}$ Por tanto, el deber de tolerancia implicaría que los terceros tampoco tuvieran un deber negativo de respeto de dicha esfera de derechos (en la medida en que ello se concretara). ${ }^{13}$ Hirsch, en Jähnke/Laufhütte/Odersky (Hrsg.), Leipziger Kommentar zum StGB, $11^{\text {a }}$ ed., Berlin 1999, § 34, nº marg. 1; Lenckner/Perron, en Schönke/Schröder, StGB Kommentar, 26 a ed., München 2001, § 34, $n^{\circ}$ marg. 1; previos al $\S 32, n^{\circ} \operatorname{marg} .10$. De modo que el sujeto afectado por el deber de tolerancia, si realiza un acto de exclusión, comete una agresión ilegítima.
} 
la esfera de derechos de otro vinculado por deberes de tolerancia con respecto a aquél no cuestiona sus derechos de libertad negativa: no vulnera las relaciones jurídicas existentes entre sus correspondientes esferas de organización. Más adelante se examinará cómo se concreta y cuáles pueden ser las consecuencias de esta observación.

\subsection{Fundamento del deber de tolerancia y estado de necesidad.}

En otras causas de justificación, como la legítima defensa, la fundamentación del deber de tolerancia puede ser, quizá, más sencilla. En el caso del estado de necesidad agresivo, en cambio, procede admitir de entrada que no resulta fácil explicar por qué un tercero ajeno a la situación de necesidad debe tolerar la intervención del sujeto necesitado o de su auxiliador, abandonando sus bienes a la acción de éstos ${ }^{14}$. Así las cosas, la cuestión relativa al fundamento del deber de tolerancia de las conductas realizadas en estado de necesidad agresivo se ha tratado de resolver por remisión a la pregunta sobre la ratio de dicho estado de necesidad. Algunos autores recurren a una fundamentación utilitarista ${ }^{15}$, para la que el deber de tolerancia del afectado se basa, como el propio estado de necesidad agresivo, en el balance social global de la acción realizada por el sujeto

\footnotetext{
${ }^{14}$ Kühl, Strafrecht AT, München 1994, 8/7. Jakobs, Sobre los grados de la incumbencia. Reflexiones sobre el origen y la importancia de los deberes de actuación y de permisión (trad. Feijóo), RPDJP 4, 2003, p. 205: “...la agresión en el estado de necesidad agresivo sucede responsablemente y por ello tendría que ser tratada conforme a las reglas de la legítima defensa. Los ámbitos de organización del beneficiado y del perjudicado no están vinculados ya conflictivamente, sino que el que se encuentra en la situación de necesidad exige a alguien con el que hasta entonces no había tenido contacto (¿por qué precisamente a él?) un sacrificio".

${ }^{15} \mathrm{Cfr}$. Meißner, Die Interessenabwägungsformel in der Vorschrift über den rechtfertigenden Notstand (§ 34 StGB), Berlin 1990, passim. Vid. otras referencias y críticas en Renzikowski, Notstand, pp. 41 y ss.; Pawlik, Notstand, pp. 32 y ss.; también en Jakobs, Strafrecht AT,

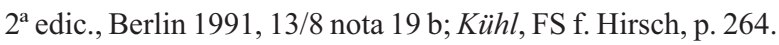


necesitado ${ }^{16}$. Sin embargo, el planteamiento utilitarista, incluidas sus variantes que tratan de integrar límites de naturaleza deontológica, ha sido mayoritariamente rechazado ${ }^{17}$. Así, un rápido examen de la doctrina pone de relieve que por lo común se alude a que el fundamento del estado de necesidad agresivo -y, por añadidura, del deber de tolerancia de terceros- se halla en el principio de solidaridad ${ }^{18}$. Partiendo de que éste muestra, de entrada, una naturaleza moral ${ }^{19}$, se ha intentado explicar su juridificación ${ }^{20}$ desde perspectivas, por un lado, contractualistas y, por el otro, institucionalistas ${ }^{21}$.

La primera perspectiva apunta que la solidaridad no es expresión de una actitud moral (que a nadie cabría exigir y que en el estado originario

${ }^{16}$ Cfr. la descripción y crítica de Kühl, AT, 1994, 8/8; asimismo, Merkel, La filosofía ¿"convidado de piedra" en el debate del Derecho Penal? (trad. Sánchez-Ostiz), en Instituto de Ciencias Criminales de Frankfurt (ed.)/Área de Derecho Penal de la Universidad Pompeu Fabra (ed. Esp.), La insostenible situación del Derecho Penal, Granada 2000, pp. 181 y ss., 191 y ss., 201 y ss.

${ }^{17}$ Por muchos, Köhler, Strafrecht AT, Berlin 1997, p. 283; Pawlik, Notstand, p. 51 y ss., con especial referencia y crítica a las tesis contemporáneas que integran la fundamentación utilitarista con otra deontológica asentada en consideraciones de solidaridad (p. 51 nota 115). ${ }^{18}$ Cfr., por muchos, Samson, en Rudolphi/Horn/Samson/Günther/Hoyer (Hrsg.), Systematischer Kommentar zum StGB, $7^{\mathrm{a}}$ ed., Neuwied 1999, $\S 34 \mathrm{n}^{\circ}$ marg. 2; Jakobs, AT, $2^{a}$ edic., 11/3. También, Frister, Die Notwehr im System der Notrechte, GA 1988, pp. 291-292; Kühl, AT, 8/9; Renzikowski, Notstand, p. 195; Pawlik, Notstand, pp. 57 y ss., 112, 120 y ss. En España, es fundamental la contribución de Baldó Lavilla, Estado de necesidad y legítima defensa, Barcelona 1994, pp. 67-68, 90 y ss., 97: solidaridad general intersubjetiva; vid. también Bacigalupo, Principios, 4ª , p. 267.

${ }^{19}$ Como es sabido, Kant lo incluía en su "Tugendlehre". Lo recuerda ahora, entre otros, Jakobs, RPDJP 4, 2003, pp. 195 y ss., 204-205.

${ }^{20} \mathrm{Kühl}$, FS f. Hirsch, p. 274-276, partiendo del carácter moral del referido deber, acaba admitiendo, bajo ciertas condiciones, su ulterior calificación como deber jurídico. Por otro lado, sobre la juridificación del deber, inicialmente moral, de socorro cfr. Sánchez-Vera GómezTrelles, Pflichtdelikt und Beteiligung, Berlin 1999, pp. 111 y ss; Alcácer Guirao, Autonomía, solidaridad y deber de socorro (Un apunte histórico), ADPCP 2000, pp. 361 y ss..

${ }^{21}$ Pawlik, Notstand, 80 y ss., 103 y ss. 
no puede darse por supuesta), sino consecuencia exclusiva de una cooperación racionalmente motivada. En otras palabras, afirma que todo egoísta racional, en el estado originario y tras el velo de la ignorancia, ha de tener buenas razones para aceptar un principio de solidaridad mínima garantizada recíprocamente ${ }^{22}$. Como se advierte, el planteamiento se mueve entre coordenadas de carácter básicamente procedimentalista.

Desde la segunda de las perspectivas mencionadas se afirma, en cambio, que el derecho de necesidad constituye la institucionalización jurídica de un deber moral de solidaridad interpersonal y, por tanto, se separa de un modelo liberal-individualista de Derecho ${ }^{23}$, para integrarse en el marco de un pensamiento comunitario ${ }^{24}$. Con todo, en este planteamiento también sigue sin quedar claro el fundamento y alcance de la institución "solidaridad".

La perspectiva institucionalista ha adquirido una nueva dimensión en recientes aportaciones que, sobre la base de la filosofía de Hegel, integran la fundamentación del estado de necesidad agresivo en una concepción del Estado como garante no sólo del derecho formal-abstracto, sino también de un derecho (material) al bienestar. Lo esencial de este planteamiento es que implica extraer la idea de solidaridad del ámbito del mundo de la vida, y de las relaciones interpersonales, para configurarla

${ }^{22}$ Especialmente, Merkel, en La insostenible situación, pp. 196 y ss., 198. Crítico con la fundamentación de Merkel, Pawlik, Notstand, pp. 67 y ss.

${ }^{23}$ Jakobs, Strafrecht, AT, $2^{\text {a }}$ edic., 11/ 3; Con matices Neumann, Nomos Kommentar zum StGB, Baden-Baden 1995, $\S 34 n^{\circ}$ marg. 9, quien añade que ello supone una limitación de los principios liberales, pero no una suspensión de la fundamentación individualista de las relaciones sujeto-sociedad.

${ }^{24}$ Renzikowski, Notstand, pp. 196-197: "Ausdruck eines Gemeinschaftsdenkens", "Ausdruck der Gemeinschaftsbezogenheit des Individuums"; también Erb, en Münchener Kommentar StGB, München 2003, § $34 \mathrm{n}^{\mathrm{o}}$ marg. 6, quien alude a una "Sozialfeindlichkeit" del sujeto que incumple el deber de tolerancia, cuya conducta no sería compatible con la referencia comunitaria del individuo. Sobre este modelo de fundamentación, centrándose en la cuestión del deber de socorro, Alcácer, ADPCP 2000, pp. 365 y ss. 
desde dentro del propio sistema jurídico-político. En este marco pueden situarse las tesis de Jakobs y de Pawlik.

Así, en su última aproximación al problema, Jakobs fundamenta el estado de necesidad agresivo y el deber de ayuda en situaciones de necesidad en que "el citoyen se tiene que ocupar de lo general", lo que presupone, más allá de una sociedad civil, "la existencia de relaciones públicas justas, es decir, un orden estatal" 25 . En otras palabras, sosteniendo que "de la idea de responsabilidad política de todos los ciudadanos se deduce el derecho y el deber de actuar para el Estado en casos de desastre sacrificando bienes de escaso valor o soportando ese tipo de acciones "26. Esta misma idea ha sido desarrollada extensamente por Pawlik, para concluir que es posible atribuir al individuo, como parte integrante de su posición de ciudadano, el deber de soportar en casos excepcionales la injerencia de terceros en la propia esfera jurídica ${ }^{27}$. Se afirma que en el estado de necesidad agresivo entran en colisión "pretensiones de libertad"28. En concreto, que en su base se halla la tensión dialéctica entre el derecho abstracto y el derecho al bienestar, ambos elementos parciales de la idea compleja de libertad jurídicamente garantizada $^{29}$. Todo ello parece implicar una modificación de la noción de libertad jurídica asentada sobre el criterio rector (estático) de separación

\footnotetext{
${ }^{25}$ RPDJP 4, 2003, p. 206: de ahí se deriva que el burgués propietario, convertido en ciudadano, tenga que soportar "en casos de desastre, y en la medida en que no se pueda conseguir ayuda estatal, menoscabos insignificantes para el mantenimiento de una tarea pública, o bien, a tener que intervenir auxiliando en una gestión de negocios sin mandato a favor del Estado".

${ }^{26}$ RPDJP 4, 2000, p. 207. Ello implica que no se trataría de solidaridad interpersonal, sino que la víctima se beneficiaría del reflejo de un deber que el ciudadano tiene respecto al Estado (p. 209).

27 Pawlik, Notstand, p. 123: "Der Eingriffsadressat wird als Räpresentant der Allgemeinheit zur Erfüllung eines Anliegens der Allgemeinheit herangezogen".

${ }^{28}$ Pawlik, Notstand, p. 103-104: "Freiheitsansprüche der Konfliktbeteiligten".

${ }^{29}$ Pawlik, Notstand, p. 26, 82-83, 88.
} 
de esferas jurídicas, fuera de la cual sólo se hallaría el principio de solidaridad mínima interpersonal, con la finalidad de atenuar los efectos del principio "casum sentit dominus".

La idea central, que me interesa resaltar, es que en el Estado moderno no cabe admitir que la distribución social de suerte y desgracia sea cosa de la naturaleza, sino que, en cierta medida, es al Estado a quien corresponde la corrección de esa distribución ${ }^{30}$. Ello tiene lugar, en general, a través de instituciones públicas organizadas ${ }^{31}$. Sin embargo, en ocasiones, éstas pueden llegar demasiado tarde; y es en este punto en el que surgen "derecho de necesidad" y "deber de tolerancia" como "cuasi-instituciones" subsidiarias ${ }^{32}$.

El deber de tolerancia aparece, en suma, como un deber cuasiinstitucional $^{33}$ dinámico, cuya función es contribuir a asegurar las condiciones reales de la libertad jurídica en aquellas situaciones límite a las que no alcanzan las medidas institucionales ordenadas de modo estático

${ }^{30}$ Pawlik, Notstand, pp. 115, 122. Obsérvese la (relativa) proximidad de esta posición con respecto a la de Köhler.

${ }^{31}$ A las que el ciudadano contribuye, en primera instancia, mediante el pago de impuestos: Pawlik, Notstand, p. 120, 180. Por ello, en realidad, si bien el derecho de necesidad puede teorizarse desde la perspectiva de la libertad jurídicamente garantizada, no es una consecuencia necesaria de ésta. En otras palabras, no pertenece al núcleo irrenunciable de un Derecho Penal moderno.

${ }^{32}$ Pawlik, Notstand, p. 104.

${ }^{33}$ Como deber (subsidiario) de contribuir al mantenimiento de un sistema de "libertad real". El estado de necesidad agresivo cumple, pues, una función de cierre ("freihändige Schließung von Lücken", p. 184). Sobre lo inadecuado de cubrir "necesidades estructurales" de una sociedad por remisión a deberes de solidaridad cfr. Papageorgiou, Schaden und Strafe, Baden-Baden 1994, pp. 206 y ss., 213. Sin embargo, conviene no olvidar que en Estados en los que el grado de institucionalización real se mantenga radicalmente lejos de su marco normativo programático, la excepción podría tener que convertirse en regla. Sentado un determinado marco jurídico (digamos, de Estado social), existe una relación inversa entre la densidad institucional existente y el papel de la "cuasi-institución" estado de necesidad agresivo. Sin embargo, el tema no puede ser desarrollado aquí. 
a subvenir a las necesidades de los ciudadanos ${ }^{34}$. Es, expresado en otros términos, un deber positivo basado en una (cuasi)institución (cuasi)estatal de incidencia subsidiaria. Pero, por lo que parece, ello sería aplicable también al deber de socorro en situaciones de peligro, de modo que entre uno y otro no se establece diferencia alguna ${ }^{35}$. Lo que habría de conducir en todo caso, según parece, a que la sanción de la infracción del deber de tolerancia fuera la propia de la infracción del deber de socorro.

\section{3. ¿Qué relación existe entre deberes de tolerancia (pasiva) y deberes de socorro (activo)?}

Si el fundamento del estado de necesidad agresivo y del deber de tolerancia que le es inherente se sitúan -ambos- exclusivamente en el marco de la idea de solidaridad (interpersonal o canalizada a través de las instituciones del Estado), entonces el deber de tolerancia no es sino una especie dentro del género de los deberes de solidaridad. A ello se suele aludir de modo no infrecuente indicando que el deber de tolerancia (Duldungspflicht) es un deber de solidaridad pasiva, paralelo al deber de solidaridad activa-Handlungspflicht-(deber de socorro) ${ }^{36}$.

\footnotetext{
${ }^{34}$ Pawlik, Notstand, pp. 112, sobre el primado de las instituciones, pp. 182 y ss. Conviene recordar que ya antes Pawlik, Unterlassene Hilfeleistung: Zuständigkeitsbegründung und systematische Struktur, GA 1995, pp. 360 y ss., había apuntado que el fundamento del deber de socorro sólo se hallaría en apariencia en la solidaridad interpersonal, mientras que en realidad se trataría de la delegación en los ciudadanos de funciones policiales.

${ }^{35}$ Cfr. Pawlik, Notstand, pp. 154-155, quien entiende incluso que el deber de tolerancia limita más la libertad del sujeto que el deber de socorro (de lo que -parece- habría que derivar que su infracción debe ser considerada más leve que la del deber general de socorro). ${ }^{36}$ Sobre la "vinculación", "paralelismo", u otras expresiones similares, Neumann, NK, § 34 n marg. 9; Erb, MünchK, § 34 n marg. 6; Baldó, Estado de necesidad, pp. 67, 99. Resulta discutible cuál de los dos deberes muestra una mayor intensidad. Mientras que para la doctrina mayoritaria sería más intenso el deber de solidaridad activa (por ejemplo,
} 
Si se examina la discusión existente en la dogmática de los delitos de omisión, la conclusión a la que llega un sector de la doctrina es, significativamente, muy similar. Así, se indica por algunos que, si bien en general el deber de socorro es un deber de actuar, que se infringe por omisión, en ocasiones, dadas las circunstancias, puede aparecer como un deber de omitir, que se infringe por acción. La infracción de deberes de tolerancia constituiría precisamente uno de los casos en los que el deber de socorro se manifiesta como un deber de omitir que se infringe por acción: uno de los supuestos de la llamada "omisión por comisión”. Así, en el conocido ejemplo de Meyer-Bahlburg, en el que el propietario cierra la puerta de su casa, que se encontraba abierta, impidiendo que entre en ella una persona a la que perseguía un perro rabioso, que acaba mordiéndola ${ }^{37}$.

Que este último caso, claramente uno de infracción del deber de tolerancia frente a una conducta de allanamiento de morada realizada en estado de necesidad agresivo, sólo se haya examinado hasta ahora desde la dogmática de la omisión de socorro, es significativo. En efecto, como es sabido, el único deber de solidaridad que ha adquirido reconocimiento autónomo como deber jurídico-penal, y eso sólo en algunos países, es el de socorro, cuya infracción es típica por la vía del delito de omisión del deber de socorro y lleva aparejada una sanción penal. Más allá de éste, los deberes de solidaridad o no son jurídico-penales o pertenecen al grupo de los deberes "desprovistos de sanción".

Pues bien, si se aceptara que la infracción del deber de tolerancia es, sencillamente, una omisión del deber de socorro en "omisión por comisión",

Hruschka, Strafrecht, p. 96), Pawlik (nota 35) apunta la posibilidad de que lo sea el deber de solidaridad pasiva, al implicar que un tercero administre la esfera de derechos del afectado. Cfr., sobre la discusión, Pawlik, Notstand, pp. 154-155, apuntando en cualquier caso la interesante posibilidad de la conversión del delito de omisión del deber de socorro en un delito de resultado, así como el incremento de su marco de pena.

${ }^{37}$ Este ejemplo ha sido recordado y revisado recientemente por Gimbernat Ordeig, La causalidad en la omisión impropia y la llamada "omisión por comisión”, ADPCP 2000, pp. 29 y ss. $75-76,77-78,82-83$. 
se haría preciso asumir las siguientes cuatro consecuencias:

a) el alcance dogmático del deber de tolerancia habría de ser redefinido en los términos del deber jurídico-penal de socorro. En aquellas situaciones de necesidad que, por un lado, fueran subsumibles en el estado de necesidad agresivo y, por otro lado, en la omisión del deber de socorro, cabría afirmar la existencia de tales deberes (jurídico-penales) ${ }^{38}$. Dicho de otro modo: si se aceptaran las premisas sentadas, más allá de los casos en que un sujeto tiene deber de socorro, dicho sujeto no tendría tampoco deber de tolerancia y, por tanto, nadie podría esgrimir frente a él un derecho de necesidad. El deber de socorro del afectado por la conducta necesaria constituiría el reverso del derecho de necesidad del sujeto que obra en estado de necesidad agresivo ${ }^{39}$.

${ }^{38} K \ddot{u ̈ h l}$, FS f. Hirsch, p. 267.

${ }^{39}$ Köhler, AT, p. 285, habla de "correspondencia": "Die allgemeine Hilfspflicht in Notlagen und die hier dargelegten Eingriffsduldungspflicht im Notstand entsprechen einander inhaltlich: Steht die Totalität des Rechtsverhältnisses für den einen in (Lebens-) Not, dann muß sich zu ihrer Abwendung das partikuläre (ersetzbare) Freiheitsdasein des anderen, insbesondere sein gegenständliches Eigentum einschränken". Ya así Jakobs,

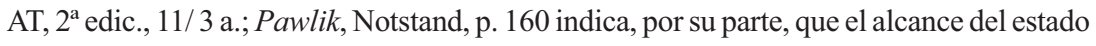
de necesidad agresivo es una cuestión cultural, situando su umbral en la actualidad (p. 161) en la amenaza de un daño que perturbe la "Lebensführung" del sujeto durante un período de tiempo relevante, y proponiendo en todo caso la orientación de los umbrales de entrada del derecho de necesidad a los del deber de socorro. También Kahlo, Die Handlungsform der Unterlassung als Kriminaldelikt, Frankfurt 2001, p. 293: "Es geht, mit anderen Worten, ausschliesslich um die endlich-zufälligen, unhintergehbaren gefährdenden Auswirkungen auf das selbständige Dasein praktischer Subjektivität, gleichsam die Kontingenzbedingungen von personaler Existenz"; asimismo, pp. 295, 305-306, 335. Por eso afirma Baldó, Estado de necesidad, p. 67 nota 91, que la coherencia del sistema se vería muy disminuida si, existiendo una regulación del estado de necesidad agresivo, no existiera una de la omisión del deber de socorro. Y, de hecho, Renzikowski, Notstand, p. 188, advierte la existencia de una relación entre la calificación -no infrecuente a principios del S. XX- de las conductas realizadas en el estado de necesidad hoy llamado justificante como meramente no prohibidas (y, por ello, susceptibles de ser repelidas en estado de necesidad o legítima defensa) y la inexistencia de una regulación general de la omisión del deber de socorro. 
b) en los ordenamientos jurídicos en los que no se hallara tipificada la infracción del deber de socorro no podría hablarse de la existencia de un deber de tolerancia en sentido estricto y, por tanto, tampoco de un auténtico derecho de necesidad. Y lo mismo habría que afirmar a propósito de aquellos ordenamientos jurídicos históricos en los que tal figura no existía ${ }^{40}$.

c) El alcance de la regulación legal del delito de omisión del deber de socorro debería tomarse como criterio para la interpretación (claramente restrictiva) del alcance del deber de tolerancia y del correspondiente derecho de necesidad en el marco general del estado de necesidad agresivo. Ello conduciría a la siguiente disyuntiva: o bien se reinterpreta el estado de necesidad agresivo (todo él) en dicho sentido, dejando fuera de la justificación a las demás conductas; o bien se admite la eficacia excluyente de la antijuricidad penal del estado de necesidad agresivo en sentido amplio, pero sosteniendo que en algunos de sus casos la conducta, a pesar de no estar prohibida, no sería constitutiva de un derecho y tampoco tendría por qué ser tolerada por el sujeto afectado.

d) En fin, la pena imponible por infracción del deber de tolerancia habría de ser sólo, y en todo caso, la propia del delito de omisión del deber de socorro.

\section{4. ¿Sólo deberes de solidaridad pasiva?}

\section{1. Introducción.}

Sin embargo, la impresión de que en los deberes de tolerancia pueda tratarse sólo de deberes de solidaridad de contenido axiológicamente idéntico al del deber de socorro activo se ve pronto

\footnotetext{
${ }^{40}$ Por ejemplo, en el ordenamiento alemán del StGB de 1871, en el que la prestación de socorro requería la intimación de la autoridad. Como sucedía, por lo demás, en el ordenamiento español anterior a la introducción del art. 489 bis en el Código Penal derogado en 1995.
} 
desmentida. Así, incluso autores que afirman -en teoría- que se trata de deberes "paralelos" a los de socorro activo, en la práctica, a la hora de establecer las consecuencias de su infracción, proponen soluciones dispares. Éstas no tienen que ver con el hecho de que las infracciones de deberes de tolerancia no están tipificadas expresamente, a diferencia de lo que sucede con el delito de omisión de socorro. Más bien, se derivan de entender que ciertas conductas infractoras del deber de tolerancia, esto es, que bloquean la conducta realizada en estado de necesidad agresivo, pueden ser conductas típicas en el sentido de los tipos de resultado de la Parte Especial. Dado que, por lo demás, dichas conductas típicas no pueden ampararse en una legítima defensa ni en otra causa de justificación, cabe sancionarlas como coacciones, lesiones ${ }^{41}$, homicidios ${ }^{42}$, daños, etc.

Para evitar malentendidos, conviene precisar ya desde este momento que, en realidad, el concepto de infracción del deber de tolerancia es lo suficientemente amplio como para que quepa incluir en él situaciones distintas, que merecen un tratamiento diferenciado. Cabe, así, en primer lugar, que la infracción del deber de tolerancia se manifieste sencillamente en la resistencia pasiva a (o en la falta de colaboración activa con) la conducta del sujeto necesitado o de su auxiliador ${ }^{43}$. En estas situaciones, que a mi entender constituyen el grupo de infracciones menos graves del

${ }^{41}$ Seelmann, Solidaritätspflichten im Strafrecht?, en Jung/Müller-Dietz/Neumann (Hrsg.), Recht und Moral. Beiträge zu einer Standortbestimmung, Baden-Baden 1991, pp. 295 y ss., 296.

${ }^{42} \mathrm{Cfr}$. el comentario de un caso de infracción de deberes de tolerancia al que se da esta solución en Hruschka, Strafrecht, pp. 83 y ss., 85 y ss.. Concretamente: tratándose de un caso de infracción del deber de tolerancia de un auxilio necesario, existe responsabilidad por la muerte del necesitado y por las coacciones ejercidas sobre el agente auxiliador.

${ }^{43}$ Entre las que, a mi juicio, habría que incluir la "omisión de impedir la interrupción por un tercero del curso causal salvador puesto en marcha por el necesitado o su auxiliador". Este caso, sin embargo, que introduce nuevos elementos de complejidad, no puede ser examinado aquí. 
deber de tolerancia, sí nos hallamos ante casos de mera infracción del deber de solidaridad mínima interpersonal, que merecen el mismo tratamiento que las omisiones de socorro.

Ahora bien, cabe, en segundo lugar, que el afectado por la conducta del necesitado o de su auxiliador no se limite a la resistencia pasiva, sino que, ciertamente manteniéndose en su esfera jurídica originaria, neutralice la conducta del necesitado o su auxiliador, ya mediante una oposición directa activa, ya mediante la sustracción de los bienes que éstos pretendían alcanzar. Esta situación, a la que esencialmente se dedican estas páginas, es distinta y más grave que la anterior. Como veremos, en ella cabe fundamentar una responsabilidad por la lesión sufrida por los bienes jurídicos del necesitado, así como por la coacción ejercida sobre el auxiliador en el caso de que éste sea alguien distinto del propio necesitado ${ }^{44}$.

Pensando, seguramente, en este segundo grupo de casos Hruschka lo expone de forma clara: el deber de tolerancia es un deber de omitir; las infracciones de deberes de omitir son delitos comisivos; por lo tanto, la infracción de deberes de tolerancia debe dar lugar a delitos de comisión ${ }^{45}$. Y Jakobs lo formula en términos paralelos: el que, sin otro motivo, guarda su bicicleta, cuando el campesino vecino la quiere utilizar para ir a buscar

${ }^{44}$ En fin, cabe, en tercer lugar, que el afectado por la conducta del sujeto necesitado o de su auxiliador infrinja su deber de tolerancia no ya sólo mediante resistencia pasiva, ni siquiera mediante la reacción activa dentro de la propia esfera originaria de organización, sino llegando incluso a injerirse en la esfera jurídica originaria de aquéllos (por ejemplo, lesionando al agente necesitado o a su auxiliador). Esta situación es todavía más grave que la anterior y permite fundamentar una responsabilidad adicional por la lesión de bienes activamente causada

${ }^{45}$ Hruschka, Strafrecht, p. 91. Para Hruschka, si lo entiendo bien, la armonía entre el delito de omisión del deber de socorro y el estado de necesidad justificante pasa más bien por interpretar la cláusula de exigibilidad de aquél en relación con el contenido de éste. Y por la siguiente conclusión: sólo puede estar obligado a socorrer en una determinada situación de necesidad aquel sujeto que estaría obligado a tolerar la actuación necesaria. Lo que, a mi entender, deja al margen el problema que nos hemos planteado aquí. 
medicamentos para su ganado enfermo, responde por infracción del deber de tolerancia, dados dolo y resultado (de muerte del ganado), por el delito de daños del $\S 303 \mathrm{StGB}$, incluso aunque no tuviera deber de socorro por no darse los presupuestos, más estrictos, del $\S 323$ c StGB ${ }^{46}$.

Como se advierte, pues, estas conclusiones parecen separarse radicalmente de las premisas sentadas en el apartado anterior. Y puede percibirse que lo que se tiene claro, en las consecuencias, es que el deber de tolerancia no es -o, al menos, no es en los casos más relevantes- un deber de solidaridad mínima, cuya infracción haya de seguir la vía del delito de omisión de socorro. Cabría que se tratara, ciertamente, de un deber positivo como este último, aunque, por lo que se infiere de la conclusión, sería un deber positivo de intensidad equiparable a la de los deberes negativos. E incluso no cabría descartar que constituyera un deber negativo.

En realidad, a pesar de no abandonar la referencia permanente al delito de omisión del deber de socorro, en el planteamiento de Pawlik se hallan elementos que permiten fundamentar conclusiones como las apuntadas: se afirma que la conducta realizada en estado de necesidad agresivo es expresión del ejercicio de un derecho al bienestar que integra, como lo hace el derecho abstracto, la idea compleja de libertad jurídicamente garantizada. Todo ello parece implicar una modificación de la noción liberal-individualista de la libertad jurídica. Ésta, en efecto, era entendida como autonomía excluyente y se asentaba sobre el criterio de la rígida separación de esferas jurídicas, fuera de la cual sólo se hallaría el principio de solidaridad mínima interpersonal, así como las formas institucionales de solidaridad cualificada, con la finalidad de atenuar los efectos del principio “casum sentit dominus". Ahora, junto a esa dimensión de libertad formal aparece una dimensión de libertad real, que, a mi juicio, debe entenderse como autorrealización.

Y otro tanto sucede con Köhler, a pesar de que tampoco este autor prescinde de la relación del deber de tolerancia con el deber de

\footnotetext{
${ }^{46}$ Jakobs, AT 7/ 63 y nota 109.
} 
socorro. En efecto, también Köhler apunta a una noción de libertad real ${ }^{47}$ como fundamento de un derecho de necesidad limitado, basado en la idea de que la existencia de una dimensión de justicia distributiva es presupuesto necesario de las relaciones jurídicas interpersonales ${ }^{48}$.

A mi juicio, a la vista de lo anterior podría formularse la siguiente hipótesis. La "situación de necesidad" constituye una institución (o cuasiinstitución) peculiar. En efecto, en este caso no se trata de la conformación de un "mundo en común” entre sujetos. Sí es cierto, en primer lugar, que en ella -y en su excepcionalidad- se fundamenta el surgimiento de deberes positivos: por un lado, el deber de socorro directo; $\mathrm{y}$, por otro lado, el deber de colaboración activa con la actuación autosalvadora del necesitado o con la conducta auxiliadora de un tercero (primera manifestación del deber de tolerancia). Ahora bien, en segundo lugar, la "necesidad" genera una peculiar dinámica en las relaciones jurídicas existentes entre diferentes esferas de organización. Dicha dinámica produce una modificación temporal y cambiante de las fronteras existentes entre dichas esferas y, consiguientemente, también de los deberes negativos que surgen en las interrelaciones de los sujetos. De ahí se deriva el deber de no interrumpir activamente las conductas autosalvadoras o auxiliadoras (segunda manifestación del deber de tolerancia).

El derecho de necesidad es, pues, entonces un derecho de libertad (real). En la medida en que se trata de un derecho excepcional, circunscrito a casos muy concretos, dicho derecho de libertad prevalece sobre la libertad formal del sujeto afectado por la conducta necesaria. Tal prevalencia da

${ }^{47}$ Köhler, AT, p. 284-285: “Die Begründung setzt die rechtliche Selbständigkeit der Personen in ihrer Pragmatik und in ihrem Gutstreben voraus".

${ }^{48}$ Köhler, AT, p. 284 alude al "freiheitsnotwendig-distributiven Gehalt des Rechtsverhältnisses", con lo que fundamenta un derecho de necesidad limitado sobre la base de consideraciones de justicia distributiva. Su concepción del derecho de necesidad lo reduce a casos límite de necesidad vital que puede resolverse a costa de bienes fungibles, reversibles o resarcibles. 
lugar, como se ha indicado, al deber de tolerancia que, por tanto, es, en esta faceta, un deber negativo. La relación entre esferas jurídicas no se rige, pues, por el modelo rígido y estático de la separación, sino que, en un ordenamiento no formalista, que considere las exigencias de la libertad real, no excluye la existencia de interferencias. Una de dichas interferencias, que modifica radicalmente la situación de partida, es la del estado de necesidad agresivo. En efecto, en su marco, lo que era una estructura “derecho de exclusión de A/deber (negativo) de respeto de B" se convierte, en términos provisionales y reversibles ${ }^{49}$, en la estructura inversa " $\mathrm{deber}$ (negativo) de tolerancia de A/derecho de injerencia necesaria de B".

\subsection{El estado de necesidad agresivo y los cursos causales salvadores.}

La perspectiva esbozada acerca de la naturaleza de la infracción de deberes de tolerancia puede verse seguramente enriquecida si se tiene en cuenta que la acción realizada en estado de necesidad agresivo ${ }^{50}$ responde a la estructura de un curso causal salvador, que inicia el propio necesitado o el tercero que le auxilie ${ }^{51}$. La peculiaridad, frente a los cursos causales salvadores atípicos y frente a los antijurídicos, es que éstos son cursos salvadores típicos pero justificados. Así las cosas, la no tolerancia pasiva (por parte del afectado o de otros terceros que actúen como gestores de sus intereses) frente a la conducta necesaria constituye la interrupción de un curso causal salvador.

Pues bien, si el sistema del Derecho Penal es, efectivamente, un sistema, entonces las soluciones doctrinales al problema de la infracción

\footnotetext{
${ }^{49}$ Köhler, AT, p. 285.

${ }^{50}$ Como también lo son la acción realizada en legítima defensa y la realizada en estado de necesidad defensivo.

${ }^{51}$ Como advirtió con claridad Baldó, Estado de necesidad, p. 183.
} 
de deberes de tolerancia en el estado de necesidad agresivo y al problema de la interrupción de cursos salvadores ajenos han de ser coherentes. Parece que a ello se refiere últimamente Jakobs, cuando indica lo siguiente: "el que deniega una cooperación obligada prosiguiendo con la organización que tenía previamente planeada (otra cosa sería si impidiera a terceras personas emprender el salvamento) no podría ser castigado por un delito de comisión por omisión, sino sólo por la existencia de una regla especial (más débil) como la que se encuentra tipificada en Alemania como delito de omisión del deber de socorro (\$323 c del Código penal alemán). En el caso del ejemplo mencionado anteriormente en el que se necesita una embarcación para salvar a una persona que se está ahogando hay que llegar a la conclusión de que el que no hace uso del bote para ese fin o no se lo proporciona a terceras personas dispuestas a socorrer o sale a pescar como tenía inicialmente planeado de tal manera que los que quieran socorrer no pueden utilizarlo es autor de un delito de omisión del deber de socorro (distinto sería el caso del que evita el salvamento -garante- lo cual es delito de comisión) "'52. Y es que, efectivamente, el hecho de si se aprecia o no la interrupción de un curso salvador resulta decisivo a los efectos del tratamiento dogmático del problema.

Ciertamente, cabría afirmar que resulta discutible que pueda llamarse curso causal salvador al que parece no poseer todavía idoneidad salvadora de los bienes del necesitado, pues para ello requiere precisamente obtener algo de la esfera organizativa de un tercero. Ello, incluso, podría dar pie a distinguir los casos en los que ya se ha accedido al bien del tercero que se necesita y es entonces cuando ello no se tolera por el afectado; y los casos en que lo que no se tolera por el tercero es el propio acceso a su esfera de organización para alcanzar la pretendida idoneidad salvadora de la conducta realizada por el necesitado. Sin embargo, si, como sucede en los casos que aquí interesan, resulta que la esfera organizativa del afectado

${ }^{52}$ Jakobs, RPDJP 4, 2003, pp. 206-207. 
se encuentra rebus sic stantibus perfectamente accesible al sujeto que obra en estado de necesidad, en la medida en que éste lo requiere, no parece que quepa poner en duda que, en tal statu quo, la conducta necesaria posee ex ante la condición de curso salvador idóneo ${ }^{53}$.

En todo caso, la situación que nos ocupa puede tener seis variantes:

a) el curso salvador iniciado por el necesitado -y, de entrada, idóneo rebus sic stantibus- es interrumpido activamente (no tolerado) por el titular de los bienes afectados.

b) el curso salvador iniciado por el necesitado -y, de entrada, idóneo rebus sic stantibus- es interrumpido activamente (no tolerado) por un tercero en favor del titular de los bienes afectados.

c) el curso salvador iniciado por un auxiliador -no garantedel necesitado -y, de entrada, idóneo rebus sic stantibus- es interrumpido activamente (no tolerado) por el titular de los bienes afectados.

d) el curso salvador iniciado por un auxiliador -no garantedel necesitado -y, de entrada, idóneo rebus sic stantibus- es interrumpido activamente (no tolerado) por un tercero a favor del titular de los bienes afectados.

e) el curso salvador iniciado por un auxiliador -garante- del necesitado -y, de entrada, idóneo rebus sic stantibus- es interrumpido activamente (no tolerado) por el titular de los bienes afectados.

f) el curso salvador iniciado por un auxiliador -garante- del necesitado -y, de entrada, idóneo rebus sic stantibus- es interrumpido activamente (no tolerado) por un tercero a favor del titular de los bienes afectados.

\footnotetext{
${ }^{53}$ Cfr. Roxin, En el límite entre comisión y omisión, en Problemas básicos del Derecho Penal (trad. Luzón Peña), Madrid 1976, pp. 226 y ss., 233, indicando que las relaciones de propiedad respecto del instrumento salvador no pueden decidir sobre la subsunción típica.
} 
Como puede observarse, las variantes se construyen en función de que quien realiza la acción en estado de necesidad agresivo sea el propio necesitado o un tercero auxiliador (que puede ser garante del necesitado o no); y en función de que quien interrumpe (no tolera) dicha acción en estado de necesidad sea el titular de los bienes afectados o un tercero que obre en favor de él. Pues bien, paradójicamente, las estructuras expuestas, que, desde el punto de vista de la dogmática del estado de necesidad, conforman variantes exentas de significado especial ${ }^{54}$, reciben, desde la dogmática de la interrupción de los cursos causales salvadores, soluciones no coincidentes en absoluto.

La doctrina dominante suele optar, si bien es cierto que con fundamentación diversa ${ }^{55}$, por sostener la imputación del resultado lesivo de los bienes del necesitado al sujeto que interrumpe el curso salvador ajeno realizado en estado de necesidad agresivo (esto es, que infringe su deber de tolerancia $)^{56}$. Sin embargo, un sector minoritario tiende a apreciar en todos -o al menos algunos- de estos casos, la solución de la mera omisión de socorro. En España, recientemente, Gimbernat ${ }^{57}$ ha construido un modelo distintivo. Así, siguiendo a Meyer-Bahlburg, ha propuesto tratar la estructura a) como una omisión del deber de socorro, con el argumento de que cabe no-socorrer tanto permaneciendo inactivo como actuando para desbaratar un proceso causal desencadenado por el sujeto desamparado, "de modo que quien cierra la puerta de una casa, donde

\footnotetext{
${ }^{54}$ Con la única matización de que en las variantes e) y f) (y, eventualmente, en las c) y d)) habría que construir una colisión de deberes.

${ }^{55}$ Cfr. las referencias en Silva Sánchez, El delito de omisión. Concepto y sistema, Barcelona 1986, pp. 227 y ss; Gimbernat, ADPCP 2000, pp. 87 y ss.

${ }^{56}$ Cfr., por ejemplo, Roxin, Problemas básicos, pp. 232 y ss, aludiendo significativamente a la existencia de una "injerencia en los esfuerzos de otro por impedir el resultado". ${ }^{57}$ ADPCP 2000, pp. 82-83. Gimbernat separa este caso de los de interrupción de cursos salvadores ajenos, aunque, sin embargo, me parece claro que en él se interrumpe un curso salvador y que éste es ajeno con respecto a quien lo interrumpe.
} 
podría haber encontrado refugio el desafortunado perseguido por los canes, está no socorriendo, no auxiliando a quien se encuentra en peligro manifiesto y grave". En cuanto a las estructuras c) y d) Gimbernat ${ }^{58}$ propone tratarlas también como omisiones del deber de socorro, en la medida en que lo interrumpido sería un curso salvador iniciado por un no-garante. En cambio, sostiene la imputación del resultado lesivo de los bienes del necesitado al infractor del deber de tolerancia en los casos e) y f), porque lo interrumpido sería un curso salvador ajeno iniciado por un garante. Queda abierto en su planteamiento el tratamiento que habría de recibir la variante b), aunque probablemente habría de ser el mismo de la variante a). Todo ello, en el marco de su concepción, que en sí me parece asumible, de que la interrupción de cursos salvadores constituye en realidad un tertium genus de realización de los tipos de resultado, distinto de la comisión activa y de la comisión por omisión en sentido estricto ${ }^{59}$.

Sin embargo, como ha puesto de manifiesto Dopico ${ }^{60}$, si Gimbernat entiende que la interrupción de los cursos salvadores llevados a cabo por un garante debe dar lugar a responsabilidad por el resultado lesivo, ello debería aplicarse también a los cursos "autosalvadores" (estructura a), pues resulta difícil negar al propio sujeto necesitado la condición de "garante de sí mismo"61. Además, incluso en los casos de interrupción de cursos salvadores ajenos de terceros no garantes (auxiliadores no garantes del

\footnotetext{
${ }^{58}$ ADPCP 2000, pp. 102 y ss.

${ }^{59}$ Gimbernat, ADPCP 2000, pp. 98 y ss. Ya Hruschka, Strafrecht, p. 74, indicando que, sin embargo, estas estructuras se tratan igual que la comisión activa y que "habría que dedicar más atención al problema en el futuro"; Joerden, Strukturen des strafrechtlichen Verantwortlichkeitsbegriffs: Relationen und ihre Verkettungen, Berlin 1988, pp. 51 y ss., alude a la causación activa y a la interrupción de cursos causales salvadores como dos variantes del concepto de acción.

${ }^{60}$ Dopico Gómez-Aller, Fundamentos de la responsabilidad por injerencia en Derecho Penal, tesis doctoral inédita, Madrid 2002, p. 1015.

${ }^{61}$ De hecho, incluso podría sostenerse que quien presta el socorro debido, e incluso quien lo hace de modo supererogatorio, se convierten, en cierta medida, en garantes por asunción.
} 
necesitado), no puede afirmarse sencillamente que el sujeto infractor del deber de tolerancia ha dejado de prestar medios propios para la evitación de un resultado lesivo que no es de su incumbencia ${ }^{62}$. En realidad, como se verá, lo que hace es injerirse en la esfera jurídica ajena, ya directamente, ya por afectarse la esfera de terceros que actúan como gestores de negocios ajenos -los del necesitado- sin mandato ${ }^{63}$.

Mi posición, criticada ahora por Gimbernat, es, desde hace dos décadas, distinta. Ciertamente, y en concordancia con lo que indica Gimbernat, me parece claro que entre la conducta de interrupción de un curso salvador ajeno (en lo que aquí interesa, de infracción del deber de tolerancia) y la producción del resultado lesivo (lesión de los bienes jurídicos del necesitado) no existe relación de causalidad ${ }^{64}$. Sin embargo, me parece difícil negar que quien interrumpe un curso causal salvador ajeno -aquí, el sujeto que no tolera la conducta realizada en estado de necesidad agresivo- produce un incremento del riesgo de producción del resultado lesivo que amenaza al sujeto necesitado ${ }^{65}$ : modifica el statu quo en perjuicio de los bienes de éste ${ }^{66}$.

Si esto es así, parece claro, también, que la situación es distinta de la de una mera omisión del deber de socorro activo, que deja intacto el statu quo ante. Ciertamente, no es lo mismo perturbar el ejercicio del derecho de necesidad (vgr. empeorar la situación de los bienes del necesitado) que no socorrer al necesitado (vgr. no mejorar la situación de sus bienes jurídicos). En mi opinión, ello implica que el sujeto que infringe el deber

\footnotetext{
${ }^{62}$ Dopico, Fundamentos, pp. 1016-1017.

${ }^{63}$ Más adelante trataré de exponer en detalle por qué puede llegar a afirmarse esto.

${ }^{64}$ Silva Sánchez, El delito, pp. 237 y ss.

${ }^{65}$ Baldó, Estado de necesidad, p. 188-189, con referencias a mi citada obra.

${ }^{66} \mathrm{Y}$ ello, tanto si quien realiza el curso causal salvador es un garante, un obligado en virtud del deber general de socorro, o un sujeto que realiza un comportamiento supererogatorio. Por ejemplo, alguien que, para ayudar al necesitado, se arriesga personalmente, con lo que la omisión de su auxilio no habría sido típica.
} 
de tolerancia se convierte en garante de aseguramiento del riesgo incrementado, que queda integrado en su esfera de organización ${ }^{67}$. Expresado de otro modo, que la infracción del deber de tolerancia es una auténtica injerencia en la esfera de derechos (de necesidad) ajena, aunque sea ésta una injerencia que no causa el resultado ${ }^{68}$. Por eso cabe imputarle al infractor el resultado lesivo de los bienes del necesitado; así como reaccionar frente a su infracción del deber de tolerancia en legítima defensa ${ }^{69}$.

\section{Sobre la necesaria redefinición del significado de las infracciones de deberes de tolerancia.}

\subsection{Introducción.}

Así pues, según entiendo, el derecho de necesidad aparece como derecho a que no se modifique el statu quo en perjuicio de los bienes jurídicos del necesitado, esto es, empeorando su situación. El deber de tolerancia sería, pues, un deber de respeto (negativo) del statu quo, tal como éste ha quedado configurado en el momento de tener lugar el curso

\footnotetext{
${ }^{67}$ No puedo desarrollar aquí cómo concibo ahora la configuración de esa responsabilidad. Sí quiero, sin embargo, remitirme a las importantes matizaciones críticas que Dopico, Fundamentos, pp. 1096 y ss., hace a mi planteamiento de 1986, buena parte de las cuales me parecen perfectamente asumibles. En particular, la de situar el momento central de la comisión por omisión en la propia conducta interruptora y no en un momento posterior, lo que, además, permite -según creo- salvar las críticas que me dirige Gimbernat (ADPCP 2000, pp. 97 y ss.). Se trataría, en efecto, de una "comisión por omisión realizada mediante acción".

${ }^{68}$ Sobre la interrupción de cursos salvadores como paradigma de injerencia dolosa, vid. $m i$ Comentario al art. 11 CP, en Cobo del Rosal (dir.), Comentarios al Código Penal, I, Madrid 1999, pp. 441 y ss., 479-480.

${ }^{69}$ Baldó, Estado de necesidad, p. 189.
} 
salvador. En este sentido, el derecho de necesidad y el correlativo deber de tolerancia serían algo más que derechos/deberes de solidaridad.

En efecto, resulta, de entrada, claro que la conducta realizada en estado de necesidad agresivo justificante es una conducta que la ley no prohíbe: es decir, es una conducta que no vulnera el principio neminem laede. Esto significa que el sujeto afectado no puede impedirla con violencia, pues "el que sin estar legítimamente autorizado impidiere a otro con violencia hacer lo que la ley no prohíbe" comete un delito de coacciones (art. $172 \mathrm{CP})^{70}$. Pero, si nos planteamos un caso en el que la conducta necesaria se proyecte sobre la propiedad ajena, precisamente el impedirla con violencia sería lo propio del derecho de exclusión que se asocia a los derechos reales ${ }^{71}$. Habría, entonces, que sostener que la acción necesaria conlleva una suspensión del derecho de propiedad del sujeto afectado. De modo que lo que en general sería ejercicio normal del derecho de exclusión de terceros se convertiría circunstancialmente en un delito de coacciones. De ser esto cierto, el deber de tolerancia del afectado sería, en este punto, un deber negativo, resultante de la inversión del derecho de propiedad y de la atribución de derechos provisionales y reversibles de cuasipropiedad al necesitado.

\subsection{La cuestión de la propiedad.}

La referencia, puramente ejemplificativa, a la propiedad no es casual. Buena parte de los casos de estado de necesidad agresivo afectan a la propiedad ajena. De hecho, el estado de necesidad agresivo jurídico-civil

\footnotetext{
${ }^{70}$ Claro está que puede que la impida mediante engaño, o, en todo caso, sin violencia, lo que excluiría esta infracción adicional y su sanción.

${ }^{71}$ Cfr. Mir Puig, El delito de coacciones en el Código Penal, RJCat 1977, pp. 777 y ss., 803 nota 99, citando a Castán: "Los derechos reales son derechos de exclusión, pues su función se reduce a conceder al titular el poder de no ser perturbado por nadie en el desempeño de su libre actividad respecto a la cosa".
} 
aparece regulado en el BGB alemán en los parágrafos correspondientes al derecho de propiedad ${ }^{72}$. Así que conviene no ignorar que las consideraciones que se efectúan en torno a los deberes de tolerancia en el marco del estado de necesidad agresivo tienen muy presente la cuestión de la propiedad. Es interesante constatar, pues, cómo las consideraciones que aquí se efectúan entroncan perfectamente con la tradicional doctrina cristiana sobre el destino común de los bienes ${ }^{73}$, de los que el propietario formal sólo es administrador, pudiendo disponer de ellos sólo en tanto y en cuanto no sean necesarios para los demás. Ello, porque "in necessitate sunt omnia communia". En efecto, como indicaba Santo Tomás de Aquino $^{74}$, debe distinguirse entre el poder de administrar y disponer, y el uso o disfrute de los bienes. El uso o disfrute de los bienes no es exclusivo del propietario porque, en cuanto al uso, el hombre no debe poseer los bienes exteriores como propios, sino como comunes, es decir, de tal manera que fácilmente los comunique a los demás, haciéndoles partícipes de ellos en caso de necesidad. Así también lo exponía más tarde entre nosotros

${ }^{72}$ Cfr., por todos, J. von Staudingers Kommentar zum Bürgerlichen Gesetzbuch mit Einführungsgesetz und Nebengesetzen, 3. Buch, 13ª edic, Berlin 1996, § $904 \mathrm{n}^{\circ}$ marg. 1, donde el referido precepto se configura como una "Eigentumsbeschränkung".

${ }^{73} \mathrm{Cfr}$. la Constitución pastoral Gaudium et Spes del Concilio Vaticano II, que indica con claridad que todo hombre tiene el derecho natural a usar de los bienes humanos que sean precisos para satisfacer sus necesidades materiales, así como que la naturaleza no vincula, de suyo, ningún bien concreto a tal o cual hombre determinado. Esta doctrina del destino común de los bienes pone de relieve, por tanto, que la propiedad no es un derecho absoluto, sino que tiene una índole social (Gaudium et Spes, 71). Con palabras gráficas se ha indicado que sobre toda propiedad pesa una "hipoteca social".

${ }^{74}$ Summa Theologiae, liber I, q. 98 a. 1 ad 3. Otras referencias a Santo Tomás y a Grocio en Renzikowski, Notstand, p. 192. Cfr., también Köhler, AT, p. 285: "In der Gefahr eines totalen Rechtsverlustes für den einen -zugespitzt in der Lebensnot, die durch partikuläre (ersetzliche) Aufopferung anderer abgewendet werden könnte- beweist der freiheitsnotwendig-distributive Gehalt des Rechts -das ursprünglich allgemeine Besitzrecht auf der Erde- seine Kraft". 
Domingo de Soto 75 : "quantum ad usum potest quammodo affirmari ius naturae praecipere omnia esse communia in necessitate" ("en cuanto al uso, puede afirmarse en cierta manera que el derecho natural dispuso que todas las cosas fueran comunes en tiempo de necesidad") ${ }^{76}$.

\subsection{Propuesta de redefinición.}

Por tanto, como se ha indicado, el deber de tolerancia aparece como un deber de respeto (negativo) del statu quo, tal como éste ha quedado configurado en el momento en que tiene lugar el curso salvador, que expresa un auténtico derecho de libertad del necesitado o su auxiliador ${ }^{77}$.

${ }^{75}$ De Iustitia et iure, liber IV, q. 3, a. 1.

${ }^{76}$ De todos modos, en algunos pasajes de Domingo de Soto no queda claro cuál es el título de ese uso, pareciendo que, más que de "justicia", se trata de "misericordia", lo que se alejaría de la idea que aquí se pretende expresar.

${ }^{77}$ Dicho derecho es tal, a pesar de que se prevea que el sujeto beneficiado por la conducta realizada en estado de necesidad agresivo (el necesitado), ha de indemnizar al afectado por los daños eventualmente sufridos por éste. Así las cosas, el deber de indemnizar al afectado (que prevé el § 904 BGB y el art. 119.3 CP) aparece, también, como una exigencia de justicia distributiva (Renzikowski, Notstand, pp. 196, 199; Pawlik, Notstand, pp. 9-10), que según algún autor habría de ser asumida por la colectividad (Jakobs, Kommentar, en Eser/ Nishihara -Hrsg.- Rechtfertigung und Entschuldigung, IV, Freiburg 1993, pp. 143 y ss., 168-169). En efecto, el derecho del afectado a recibir una compensación es el que, en la dinámica de relaciones jurídicas desencadenada por la necesidad, pasa a sustituir al originario ius excludendi, que desaparece al ceder ante el derecho de intromisión del necesitado o su auxiliador (J. von Staudingers Kommentar BGB, 3., 13ª ed., $\S 904$ n $^{\circ}$ marg. 3, 33 y ss.). Y el deber de compensar tiene por objeto resarcir al afectado del uso o consumo de sus bienes llevado a cabo por el agente (enriquecimiento sin causa).

La opinión contraria a la que aquí se apunta la sostiene Feinberg. Rights, Justice and the Bounds of Liberty, Princeton 1980, p. 230, quien, sobre la base de la existencia del referido "duty of compensation", llega a la conclusión de que la acción necesaria lesiona derechos y no es, por tanto, en sí misma, ejercicio de un auténtico derecho. Feinberg admite, ciertamente, la posibilidad de que en casos de estado de necesidad agresivo, como claramente lo es el ejemplo que propone (un sujeto que para salvar su vida en medio de una tempestad 
Mientras tanto, en el caso del sujeto que se encuentra en situación de peligro abocado al socorro ajeno, se trata de un derecho (de solidaridad) a la modificación positiva del statu quo, modificación que habrá que emprender para socorrer.

La radicalidad de la distinción (que no pretende descartar la existencia de una zona gris de situaciones intermedias graduales) puede sorprender. Ciertamente, se podría afirmar, para relativizar la distinción trazada, que en ambos casos la salvación de los bienes del necesitado hace necesario el concurso de una esfera jurídica ajena. La cuestión habría de plantearse, pues, en los siguientes términos: ¿por qué un sujeto habría de estar obligado, más allá de por puras razones de solidaridad, a no modificar un determinado statu quo en su propia esfera de organización?

A mi juicio, como he sugerido más arriba, porque el curso salvador iniciado en virtud de la conducta del sujeto necesitado o de su auxiliador -el derecho de necesidad ejercido- supone el establecimiento de una relación de interferencia de esferas de organización. Expresado de otro modo, el estado de necesidad agresivo implica una redefinición provisional, circunstancial (y sólo a los estrictos efectos de la actuación necesaria) de las esferas de organización respectivas de agente y sujeto pasivo ${ }^{78}$. Ello

que le sorprende en la montaña, entra en una cabaña ajena, que ocupa mientras dura la tormenta, sirviéndose de la comida y de los muebles para hacer fuego) no se hayan lesionado "actual rights", sino sólo "prima facie rights". Concretamente: "It will be said, perhaps, that the undeniable right of the homeowner, when fully specified, excludes emergency circumstances such as the ones that obtained'. Sin embargo, acaba descartándolo porque entiende que, si no se hubiera lesionado derecho alguno, no existiría un deber de indemnización, que sin embargo a su juicio concurre en estos casos. En el mismo sentido Jarvis Thomson, Rights and Compensation, en su Rights, Restitution and Risk, Cambridge (Mass.) 1986, pp. 66 y ss., 71.

${ }^{78}$ Según creo, es próxima a esta idea la afirmación de Renzikowski, Notstand, p. 191, quien, a propósito del estado de necesidad agresivo jurídico-civil del $§ 904$ BGB señala: "Soweit das Eingriffsrecht des Gefährdeten reicht, wird die Grenze zwischen seiner Rechtssphäre und der Rechtssphäre des Eigentümers neu gezogen. §904 ist somit ein intrasystematischer Rechtfertigungsgrund, weil er die Abgrenzung der 
significa que la esfera de organización del sujeto pasivo, en tanto que necesaria para salvaguardar los bienes del sujeto activo, se transfiere a la esfera de actividad de éste. Así, el necesitado o su auxiliador, operando en la esfera de organización ajena, estaría ejerciendo sin embargo su propia libertad de organización (directamente -en el caso del agente necesitado- o como gestor de negocios ajenos -en el caso del auxiliador-). Y el afectado o tercero que impidiere su actuación estaría paradójicamente infringiendo el principio de separación de esferas dinámicamente concebido: estaría lesionando un deber negativo.

Con todo, creo que puede introducirse todavía una precisión adicional en lo anterior. En efecto, si el afectado por el estado de necesidad agresivo, al actuar sobre su esfera originaria de organización, se limita a proseguir con la gestión de dicha esfera jurídica de un modo neutral, tal como lo tenía previsto de forma más o menos automática, y con ello resulta que impide la conducta del sujeto necesitado o de su auxiliador, su conducta infractora del deber de tolerancia es sólo constitutiva de una omisión de socorro, aunque lo sea en la forma de "omisión por comisión"79.

Ahora bien, si el afectado por el estado de necesidad agresivo procede a una reorganización ad hoc de su esfera de actividad en función de la acción realizada por el necesitado o su auxiliador, entonces su conducta tiene inequívocamente el sentido de la interrupción de un curso causal salvador, lo que debería dar lugar a responsabilidad por el resultado.

Freiheitsbereiche bestimmt”. Y también: "Im Notstandsfall verschieben sich die Grenzen der gegenseitig abgegrenzten Freiheitssphären". Aunque también Renzikowski parece establecer una correspondencia entre el $\S 904$ BGB y el $\S 323 \mathrm{c} \mathrm{StGB}$, cuya exactitud no se comparte aquí.

${ }^{79}$ Porque el carácter estandarizado de la conducta determinaría que el incremento del riesgo producido no fuera jurídico-penalmente relevante, con lo que sólo quedaría la dimensión de estricta solidaridad que se halla en la base de los deberes de tolerancia (deber de colaborar activamente). Dicha omisión de socorro podría entenderse, con todo, como cualificada. 
En suma, el deber de tolerancia es, en esta dimensión que he pretendido resaltar, parte integrante del deber, más general, de no organizar (o reorganizar) la propia esfera jurídica de modo tal que de ello se derive un incremento del riesgo para terceros (un empeoramiento de la esfera jurídica de éstos). Aunque no estoy del todo seguro de que nuestros puntos de vista sean coincidentes, me ha parecido hallar elementos de una exposición en cierto modo próxima a la efectuada en el Tratado de Jakobs ${ }^{80}$, cuando este autor indica que el círculo de organización de un sujeto alcanza hasta donde llega el derecho de éste, en su caso ejercitable mediante derecho de necesidad, a una configuración sin impedimentos. Añadiendo, a continuación, que el derecho de disposición sobre el propio círculo de organización cesa en los casos en que existe un deber de tolerancia ${ }^{81}$.

\section{Observación final.}

El esbozo efectuado no agota, naturalmente, el conjunto de problemas propios de la dogmática de la infracción de deberes de tolerancia de conductas en estado de necesidad agresivo. A algunos de ellos se ha hecho sucinta mención en notas a pie de página. Pero existen muchos más. Por ejemplo, los relativos a la distinción entre infracciones dolosas e

80 "schon die Duldungspflicht allein nimmt das Bestimmungsrecht über die Organisationsgestalt": Jakobs, AT 7/ 63, con referencia (nota 109) a la posición coincidente de Roxin y de Armin Kaufmann, así como a las divergentes de Meyer-Bahlburg, Ranft y Herzberg.

${ }^{81}$ Jakobs, AT 7/ 63: “(der Organisationskreis) endet also schon bei Duldungspflichten (etwa aus $\$ 34$ StGB)”, con independencia de que a éstos no les corresponda ningún deber de actuar, un deber de actuar propio (general o de garante) o un deber de actuar de terceros. Añadiendo que un deber de tolerancia no implica que el propietario del bien esté obligado a mantener el bien afectado permanentemente dispuesto: "vor dem Beginnn des zu duldenden Eingriffs kann er darüber beliebig verfügen". 
imprudentes $^{82}$ (o ni siquiera imprudentes) del deber de tolerancia; así como los que aluden a la diferencia entre infracciones consumadas e intentadas del referido deber. En esta última línea aparecen también las cuestiones que suscita el desistimiento de la infracción intentada del deber de tolerancia mediante actos positivos de salvamento de los bienes del necesitado. En realidad, si bien se observa, se trataría de analizar los problemas que plantea la infracción del deber de tolerancia de conductas necesarias como forma de realización de los tipos de la Parte Especial. Todo ello deberá ser objeto de una investigación específica.

\footnotetext{
${ }^{82}$ Silva Sánchez, El delito, pp. 243-244. Las infracciones imprudentes del deber de tolerancia constituyen interrupciones imprudentes de un curso causal salvador ajeno. De modo que si, tras ellas, el sujeto infractor del deber de tolerancia dolosamente no presta socorro al necesitado, la situación debe reconducirse a las omisiones de gravedad intermedia, naturalmente en concurso con la responsabilidad imprudente por la lesión sufrida por los bienes del necesitado.
} 